\title{
Understanding uptake of prevention and mitigation of COVID-19 at work actions in Iran
}

\author{
Vahid Gharibi $^{\mathrm{a}, \mathrm{b}, 1}$, Rosanna Cousins ${ }^{\mathrm{c}, 2}$, Mehdi Jahangiri ${ }^{\mathrm{a}, *}$ and Mina Bargar ${ }^{\mathrm{a}}$ \\ ${ }^{a}$ Department of Occupational Health, School of Health, Shiraz University of Medical Sciences, Shiraz, Iran \\ ${ }^{\mathrm{b}}$ School of Public Health, Shahroud University of Medical Sciences, Shahroud, Iran \\ ${ }^{\mathrm{c}}$ Department of Psychology, Liverpool Hope University, Liverpool, UK
}

Received 7 December 2020

Accepted 12 July 2021

\begin{abstract}
.
BACKGROUND: The coronavirus disease 2019 (COVID-19) pandemic has required organizations to make changes to ways of working to prevent and mitigate COVID-19 in employees.

OBJECTIVE: To assess the workplace response to COVID-19 in Iran.

METHODS: 255 organizations completed a two-part survey. Part 1 collected data describing the business; part 2 comprised the International Labor Organization (ILO) 30-item Prevention and Mitigation of COVID-19 at Work Actions Checklist. A four-point Likert scale was used to score each item according to whether preventative measures had been actioned.

RESULTS: We found a dichotomy of commitment to managing COVID-19 at work. $42.5 \%$ of organizations had fully implemented the ILO recommended preventative actions, and $45.6 \%$ workplaces had not implemented any. Large organizations had significantly more preventative actions than SMEs; the healthcare sector had significantly better COVID-19 mitigation measures in place than construction projects; and organizations with a health and safety management system had significantly more prevention actions in place.

CONCLUSIONS: ILO provided a good framework to support risk assessment of COVID-19, however only half the organizations were undertaking the necessary biological hazard control actions to prevent COVID-19 at work. There remains a need to understand the inaction of organizations who do not risk assess despite being in a pandemic.
\end{abstract}

Keywords: Coronavirus, duty of care, ILO checklist, pandemic, risk assessment

\section{Introduction}

Coronavirus disease 2019 (COVID-19) is a new infectious disease which was first formally identified in December 2019 in Wuhan, China. This disease is

\footnotetext{
${ }^{1}$ ORCID: 0000-0002-9974-3060.

${ }^{2}$ ORCID: 0000-0003-4829-5138.

*Address for correspondence: Mehdi Jahangiri, Department of Occupational Health, School of Health, Shiraz University of Medical Sciences, Shiraz, Iran. E-mail: jahangiri_m@sums.ac.ir; ORCID: 0000-0002-4703-2523.
}

caused by coming into contact with SARS-CoV-2, a new coronavirus. On 11th March 2020, the World Health Organization announced COVID-19 as a pandemic. By the end of March 2020, there were over 800,000 confirmed cases and about 40,000 fatalities across the globe [1]. At the time of writing this paper there were more than 100,000,000 confirmed cases of COVID-19 and approaching three million deaths across 217 countries. The disease is still spreading, and the number of cases is increased every day. In Iran, the first cases of COVID-19 disease were 
confirmed February 19, 2020. The results of real-time polymerase chain reaction (PCR) tests for two people who had died in Qom were positive for COVID-19. The disease had spread to 19 of the 31 provinces of Iran by the middle of March, and by 1st April 2020, laboratory-confirmed case numbers had escalated to 47,593 . 15,473 people were confirmed as recovered, and 3,036 deaths had been recorded. By 30th May 2020 - the time this study was carried out a World Health Organization "Situation Report" indicated that these numbers had reached 148,950 cases, 116,827 recovered, and 7,734 deaths, and the disease had spread across the whole of Iran [2].

To decrease and slow the spread of COVID-19, biological hazard control actions were introduced in many nations, with varying degrees of legislative support and enforcement. These measures included social distancing, emphasizing good hand hygiene, a requirement to use face masks in public, restrictions on public transport and the closure of many commercial, industrial, and educational centers. There was a lockdown of large parts of a nation's infrastructure in at least 49 countries [3] as part of the effort to reduce the transmission of the coronavirus [4].

It soon became clear that suppression of the coronavirus would be difficult, and that lockdown measures put unsustainable pressure on the world of work and economies [1,5], education [6] and quality of life [7]. In addition, lockdown cannot ever be complete, as not all work can be conducted at home, or in isolation. Thus, efficient occupational health and safety management systems (OHSMS) were needed to manage the new biological hazard that now had the status of pandemic $[8,9]$. In addition, the significant negative economic, social and political consequences of quarantine, social-distancing and lockdown, initiated calls for a safe re-opening of labor market activity, even while suppressing the health risks from the coronavirus was ongoing [9-11].

A focus on health and safety at work is appropriate in the context of a pandemic because work supports national, local and personal economies and health [9-11]. COVID-19 presents a challenge for occupational health because there is a long list of jobs that involve direct contact with the public, or physically close contact to other workers. Moreover, COVID19 can be considered as an occupational disease where there is clear exposure to the coronavirus, as a biological agent [8], arising from poorly controlled work activities [11]. On 22nd March 2020, the World Health Organization published an interim guidance which outlined critical preparedness, readiness and response actions for COVID-19 [12]. This document argued that all countries should immediately increase their preparedness and put into place the given measures to reduce the transmission of COVID-19. To support this, in May 2020, the International Labor Organization (ILO) published a policy brief which outlined a safe and healthy return to work during the COVID-19 pandemic [11]. This document pointed out that existing labor standards and associated guidelines published in 2001 [13] provide a framework that could be used to develop systems and procedures to ensure workplaces can safely manage COVID19 as a part of their business operations. The ILO brief explained how elements of occupational health and safety management systems can be suitable and sufficient to prevent the spread of the highly contagious coronavirus in a workplace [11]. In advance of the brief (9th April 2020), the ILO formally released their 30-item Prevention and Mitigation of COVID19 at Work Action Checklist (PMAC; Appendix) [14], with an announcement that this OHSMS tool could be used to support workplace risk assessments to control the risk of catching and spreading COVID19 [11].

In the context of rising case numbers of deaths from COVID-19, in this paper we report research which examined the uptake of the ILO tool towards managing COVID-19 in workplaces in Iran during the last week of May 2020. The aim was to investigate the status of OHSMS, and the implementation of preventive measures against COVID-19 based on the ILO Prevention and Mitigation of COVID-19 at Work Actions Checklist.

\section{Methods}

Ethical approval for the study was granted by the Ethics Committee of Shiraz University of Medical Sciences (ID: IR.SUMS.REC.1400.395).

\subsection{Study design and participants}

The study used a cross-sectional analytical survey design. The research aim, objectives, procedures and the information commitment of the online survey were distributed in electronic announcements among companies/organizations across a large area of Iran. Formal electronic consent to participate was received from both managers and employee representatives of 255 organizations from a variety of industries. Participation required completion of an online survey 
by the person responsible for health and safety in the organization. If there was not such a person, we asked a senior manager to complete the survey.

\subsection{Measures}

The first part of the survey asked for data on the size (small to medium enterprise (SME), if fewer than 99 workers, or large enterprise if 100 workers or more [15]), type (private, semi-private or government), and the activity of the business (to enable classification of businesses by sector), as well as organizational and managerial parameters including health and safety specialist recruitment, the presence of a formal occupational health and safety management system (OHSMS) and senior manager support for prevention programs.

The second part examined prevention and mitigation of COVID-19 activity using the 30-item PMAC [14]. The ILO provides the survey tool in 21 languages. The Arabic and English versions were separately converted to Persian by two University professors to agree and confirm an appropriate translation for the participants. The PMAC has four dimensions: policy, planning and organizing (11 items); risk assessment, management and communication (7 items); prevention and mitigation measures (9 items); and arrangements for suspected and confirmed COVID-19 cases ( 3 items). A four-point Likert scale was used to score the scale items as follows:

0 - Preventive measures have not been started and the organization has no plan for implementing preventive measures in the future;

1 - Preventive measures have not been started but there are plans in place to implement preventive measures in the near future;

2 - Preventive measures are in progress, but not sufficiently completed;

3 - Preventive measures are completed and implementation is being continuously monitored.

Thus, high scores are good, and low scores are poor.

\subsection{Statistical analyses}

Data records obtained through the online survey were stored in Microsoft Excel, then imported into SPSS statistics 24 (SPSS Inc., USA) for statistical analyses. Descriptive analyses including mean (standard deviation) and frequency (percent) were performed for all four dimensions, and the whole tool score. Assumptions of normality were met, and independent $t$-tests, ANOVA, and Pearson product moment correlation tests were used to examine the relationships between the dimensions of PMAC and independent variables. The conventional alpha level of $\leq 0.05$ was considered as significant. Multivariate linear regression was used to determine the predictive variables of the dimensions of the PMAC.

\section{Results}

255 organizations in more than seven different sectors returned a completed survey. About half (50.6\%) were SMEs and half (49.4\%) employed more than 100 employees. 54 representatives of industries and organizations $(21.2 \%)$ were familiar with the ILO checklist, and 201 representatives (78.8\%) were completing the checklist for the first time. The total mean scores of the PMAC and its four dimensions are shown in Table 1.

Regardless of dimension, $18.06 \%$ of workplaces had not implemented any of the preventive measures and $29.71 \%$ workplaces had not implemented preventive measures but reported that they were going to implement them in the future. Thus $47.77 \%$ of the studied workplaces in Iran had not implemented any of the prevention and mitigation of COVID-19 at work actions recommended by ILO at this time in the pandemic.

$12.47 \%$ of organizations had implemented some prevention and mitigation measures, and $42.48 \%$ of the workplaces had implemented all prevention and mitigation of COVID-19 at work actions recommended by ILO, successfully and completely.

Table 2 reports the frequency distribution of organizational and managerial parameters of occupational safety and health management systems (OHSMS) and their association with dimensions of PMAC varied in workplaces. The businesses' size, sector, health and safety specialist recruitment, development of management systems, and senior manager support for prevention programs were significantly correlated with the mean score of PMAC $(p<0.05)$. Regardless of dimension, prevention and mitigation of COVID19 activity was highest in the healthcare sector and lowest in the construction sector.

Multivariate linear regression was used to determine the predictors of PMAC (see Table 3). The results showed that SMEs, construction projects, companies without a health and safety specialist, companies without an established OHSMS, and 
Table 1

Frequency distribution and mean score of dimensions of the PMAC among study groups

\begin{tabular}{|c|c|c|c|c|c|c|c|c|}
\hline \multirow[t]{2}{*}{ Dimension } & \multirow{2}{*}{$\begin{array}{c}\text { Number } \\
\text { of } \\
\text { items }\end{array}$} & \multirow{2}{*}{$\begin{array}{l}\text { Not done; } \\
\text { no plans to } \\
\text { implement }\end{array}$} & \multirow{2}{*}{$\begin{array}{l}\text { Not done; } \\
\text { plans to } \\
\text { implement in } \\
\text { the future }\end{array}$} & \multirow{2}{*}{$\begin{array}{l}\text { Partially done; } \\
\text { need to } \\
\text { complete and } \\
\text { improve }\end{array}$} & \multirow{2}{*}{$\begin{array}{c}\text { Fully } \\
\text { implemented, } \\
\text { constantly } \\
\text { monitoring }\end{array}$} & \multicolumn{3}{|c|}{ Score } \\
\hline & & & & & & Range & Mean $( \pm \mathrm{SD})$ & $\begin{array}{l}\text { Item mean } \\
(\max 3)\end{array}$ \\
\hline $\begin{array}{l}\text { Policy, planning and } \\
\text { organizing }\end{array}$ & 11 & $15.11 \%$ & $34.80 \%$ & $14.40 \%$ & $35.69 \%$ & $0-33$ & $18.77 \pm 8.79$ & 1.71 \\
\hline $\begin{array}{l}\text { Risk assessment, } \\
\text { management and } \\
\text { communication }\end{array}$ & 7 & $14.68 \%$ & $24.82 \%$ & $14.51 \%$ & $45.99 \%$ & $0-21$ & $13.43 \pm 6.19$ & 1.92 \\
\hline $\begin{array}{l}\text { Prevention and mitigation } \\
\text { measures }\end{array}$ & 9 & $15.12 \%$ & $30.54 \%$ & $9.76 \%$ & $44.58 \%$ & $0-27$ & $16.55 \pm 8.61$ & 1.84 \\
\hline $\begin{array}{l}\text { Arrangements for COVID-19 } \\
\text { cases }\end{array}$ & 3 & $27.32 \%$ & $20 \%$ & $9.02 \%$ & $43.66 \%$ & $0-9$ & $5.07 \pm 3.44$ & 1.69 \\
\hline Total & 30 & $18.06 \%$ & $29.71 \%$ & $12.47 \%$ & $42.48 \%$ & $0-90$ & $53.82 \pm 25.84$ & 1.79 \\
\hline
\end{tabular}

companies without the necessary senior manager support were predictors of a low mean score of PMAC across all dimensions compared with other groups.

\section{Discussion}

In this study, we evaluated the rate of prevention and mitigation of COVID-19 action at work according to ILO recommendations $[11,14]$, with the aim of understanding whether workplaces were COVID-19 safe and where hazards may remain. We found that just over half of the 255 workplaces that contributed data had implemented some prevention and mitigation actions in line with ILO recommendations, and nearly half of the organizations had not implemented any prevention and mitigation actions in their workplaces at all, despite the ongoing pandemic [2]. This is a huge concern for the controlling the COVID-19 pandemic [9].

Whilst the pandemic persists, and to avoid future outbreaks of the coronavirus, it is essential to have a high percentage of organizations across all sectors achieve a high score in implementing all four dimensions of the PMAC. Even though a COVID-19 vaccination program is under way in many countries, there is common knowledge of its ability to mutate into multiple variants, so it remains that following ILO recommendations is appropriate for preventing and mitigating the disease caused by coronavirus. In this study, assurance of good risk assessment and control measures being in place to manage COVID-19 in workplaces, would have been realized if most organizations provided confirmation that the PMAC items had been be fully implemented in their workplace.
However, we found considerably less than half of organizations had fully implemented the PMAC. Moreover, one third of these had no plans for preventative and mitigation for COVID-19 at work actions. This attitude to risk assessment and health and safety is concerning, if in line with other observations that health and safety is seen as a hassle [8], rather than a lifesaver.

These results may be from one country, and we cannot claim they are generalizable. We can, however, suggest that they may be indicative of a general situation, and that replication in other places may be very useful to understand the extent of the challenge of undertaking appropriate prevention and mitigation actions for COVID-19 in workplaces. The ILO certainly suggested that the checklist was needed internationally, and even arranged translation into a large number of languages [11, 14].

Among the four dimensions of the PMAC, arrangements for suspected and confirmed COVID19 cases and risk assessment, management and communication had the highest and lowest rates of workplaces that had not yet implemented the recommended preventive measures respectively. Similarly, risk assessment, management and communication had the highest rates of the workplaces that had completely implemented prevention and mitigation of COVID-19 at work actions. It remains, however, that even for risk assessment, management and communication more than half of our sample of organizations could be doing more. Mohammadfam et al. [16] examined the importance of risk assessment, management and communication in a study that compared three companies that had a certified occupational health and safety management system (OHSMS), 
Table 2

Frequency of organizational and managerial (OHS) parameters and relationship with the dimensions of the Prevention and Mitigation of COVID-19 at Work Action Checklist (PMAC)

\begin{tabular}{|c|c|c|c|c|c|c|c|c|c|c|}
\hline \multirow[t]{3}{*}{ Variable } & & \multirow[t]{3}{*}{$\mathrm{N}(\%)$} & \multicolumn{8}{|c|}{ Dimensions of the PMAC } \\
\hline & & & \multicolumn{2}{|c|}{$\begin{array}{l}\text { Policy, planning } \\
\text { and organizing } \\
\text { (Score range: } 0-33 \text { ) }\end{array}$} & \multicolumn{2}{|c|}{$\begin{array}{l}\text { Risk assessment, } \\
\text { management and } \\
\text { communication } \\
\text { (Score range: } 0-21)\end{array}$} & \multicolumn{2}{|c|}{$\begin{array}{c}\text { Prevention and } \\
\text { mitigation } \\
\text { measures } \\
\text { (Score range: } 0-27 \text { ) }\end{array}$} & \multicolumn{2}{|c|}{$\begin{array}{l}\text { Arrangements for } \\
\text { COVID-19 cases } \\
\text { (Score range: } 0-9 \text { ) }\end{array}$} \\
\hline & & & Mean $( \pm$ SD $)$ & $p$-value & Mean $( \pm$ SD $)$ & $p$-value & Mean $( \pm$ SD $)$ & $p$-value & Mean $( \pm$ SD $)$ & $p$-value \\
\hline \multirow[t]{2}{*}{ Size of company } & SME & $129(50.6)$ & $14.21(8.10)$ & 0.001 & $10.66(6.07)$ & 0.001 & $12.43(8.18)$ & 0.001 & $3.50(3.23)$ & 0.001 \\
\hline & Large & $126(49.4)$ & $23.44(6.82)$ & & $16.26(4.92)$ & & $20.77(6.82)$ & & $6.67(2.84)$ & \\
\hline \multirow[t]{3}{*}{ Type of business } & Private & $141(55.3)$ & $15.53(8.50)$ & 0.08 & $11.17(5.96)$ & 0.15 & $12.60(8.22)$ & 0.26 & $3.42(3.28)$ & 0.83 \\
\hline & Semi-private & $52(20.4)$ & $21.15(7.69)$ & & $15.48(5.17)$ & & $20.52(6.98)$ & & $6.62(2.60)$ & \\
\hline & Governmental & $62(24.3)$ & $24.15(6.95)$ & & $16.84(5.35)$ & & $22.21(5.54)$ & & $7.53(2.14)$ & \\
\hline \multirow[t]{7}{*}{ Sector } & Services & $16(6.3)$ & $22.75(5.32)$ & 0.001 & $17.69(2.52)$ & 0.001 & $24(2.70)$ & 0.001 & $7.94(1.28)$ & 0.001 \\
\hline & Health care & $27(10.6)$ & $28.33(10.6)$ & & $19.33(7.07)$ & & $25.81(9.12)$ & & $8.07(3.67)$ & \\
\hline & Production/Industrial & $73(28.6)$ & $20.56(10.6)$ & & $14.11(6.84)$ & & $18.29(8.69)$ & & $5.53(3.23)$ & \\
\hline & Administrative/Educational & $63(24.7)$ & $20.78(1.43)$ & & $15.63(1.42)$ & & $17.11(0.93)$ & & $5.08(0.54)$ & \\
\hline & Construction & $40(15.7)$ & $10.58(7.23)$ & & $11.83(6.39)$ & & $11.30(7.20)$ & & $3.43(0.95)$ & \\
\hline & Process industries & $27(10.6)$ & $25.96(3.45)$ & & $18.81(3.01)$ & & $23.19(2.37)$ & & $7.96(1.65)$ & \\
\hline & Other groups & $9(3.5)$ & $21.89(9.30)$ & & $16.22(7.06)$ & & $19.33(8.50)$ & & $6.44(2.65)$ & \\
\hline \multirow{3}{*}{$\begin{array}{l}\text { Employment status of } \\
\text { expert }\end{array}$} & No & $73(28.6)$ & $9.58(2.06)$ & 0.001 & $7.40(2.57)$ & 0.001 & $6.90(1.40)$ & 0.001 & $1.32(1.11)$ & 0.001 \\
\hline & Yes, parttime & $46(18)$ & $14.35(7.37)$ & & $10.17(5.81)$ & & $12.87(8.46)$ & & $3.78(3.43)$ & \\
\hline & Yes, fulltime & $136(53.3)$ & $25.21(5.58)$ & & $17.76(3.91)$ & & $22.97(4.26)$ & & $7.52(1.87)$ & \\
\hline \multirow[t]{4}{*}{ Formal OHSMS } & No & $119(46.7)$ & $12.32(5.95)$ & 0.001 & $9.33(4.74)$ & 0.001 & $10.26(6.83)$ & 0.001 & $2.79(2.76)$ & 0.001 \\
\hline & Previously & $3(1.2)$ & $20(5.19)$ & & $13.51(1.73)$ & & $14.65(2.30)$ & & $5.36(1.73)$ & \\
\hline & Implementing & $29(11.4)$ & $22.48(9.71)$ & & $16.4(7.60)$ & & $17.45(8.86)$ & & $7.26(3.91)$ & \\
\hline & Yes & $104(40.8)$ & $25.84(4.99)$ & & $18.08(3.42)$ & & $23.33(3.81)$ & & $8.60(1.90)$ & \\
\hline \multirow{3}{*}{$\begin{array}{l}\text { Senior manager support } \\
\text { of preventive programs }\end{array}$} & No & $100(39.2)$ & $9.58(2.44)$ & 0.001 & $7.51(2.96)$ & 0.001 & $6.83(1.40)$ & 0.001 & $1.35(1.30)$ & 0.001 \\
\hline & Yes, inappropriate & $41(16.1)$ & $19.90(6.78)$ & & $13.51(5.74)$ & & $20.95(5.80)$ & & $6.83(2.08)$ & \\
\hline & Yes, appropriate & $114(44.7)$ & $26.19(5.10)$ & & $18.59(3.02)$ & & $23.49(3.71)$ & & $7.90(1.82)$ & \\
\hline
\end{tabular}


Table 3

Multivariate linear regression of organizational and managerial (OHS) parameters as predictor factors of dimensions of the Prevention and Mitigation of COVID-19 at Work Action Checklist (PMAC)

\begin{tabular}{|c|c|c|c|c|c|c|c|c|c|}
\hline \multirow[t]{3}{*}{ Variable } & & \multicolumn{8}{|c|}{ Dimensions of the PMAC } \\
\hline & & \multicolumn{2}{|c|}{$\begin{array}{l}\text { Policy, } \\
\text { planning } \\
\text { and } \\
\text { organizing }\end{array}$} & \multicolumn{2}{|c|}{$\begin{array}{c}\text { Risk } \\
\text { assessment, } \\
\text { management } \\
\text { and } \\
\text { communication }\end{array}$} & \multicolumn{2}{|c|}{$\begin{array}{l}\text { Prevention } \\
\text { and } \\
\text { mitigation } \\
\text { measures }\end{array}$} & \multicolumn{2}{|c|}{$\begin{array}{l}\text { Arrangements } \\
\text { for } \\
\text { COVID-19 } \\
\text { cases }\end{array}$} \\
\hline & & B & SE & $\beta$ & SE & B & SE & B & SE \\
\hline Size of the company & SME vs large & $-13.01^{* *}$ & 1.75 & $-9.89^{*}$ & 0.98 & $-9.72^{*}$ & 0.68 & $-4.23^{* *}$ & 1.25 \\
\hline \multirow{2}{*}{$\begin{array}{l}\text { Type of business } \\
\text { ownership }\end{array}$} & Private vs governmental & 1.53 & 6.85 & -1.88 & 4.56 & 0.83 & 5.14 & 2.84 & 7.44 \\
\hline & Semi-private vs governmental & 2.76 & 8.14 & 0.71 & 5.05 & 3.14 & 7.45 & 0.41 & 3.14 \\
\hline \multirow[t]{6}{*}{ Sector } & Services vs health care & 0.13 & 6.14 & 1.04 & 5.42 & 0.79 & 10.24 & -0.02 & 7.41 \\
\hline & $\begin{array}{l}\text { Production/industrial vs } \\
\text { health care }\end{array}$ & -2.61 & 7.26 & 0.42 & 2.63 & 1.08 & -7.56 & 0.35 & 3.36 \\
\hline & $\begin{array}{l}\text { Administrative/educational vs } \\
\text { health care }\end{array}$ & 1.78 & 5.52 & -0.95 & 3.85 & 8.36 & 7.19 & 0.82 & 4.42 \\
\hline & Construction vs health care & $-19.89^{* *}$ & 1.98 & $-7.89^{*}$ & 0.41 & $-8.71^{*}$ & 0.62 & $-4.19^{*}$ & 1.18 \\
\hline & $\begin{array}{l}\text { Process industries vs health } \\
\text { care }\end{array}$ & 1.81 & 5.42 & 0.82 & 3.71 & 4.41 & 8.72 & 1.56 & 7.82 \\
\hline & Other groups vs health care & 2.52 & 9.36 & 1.04 & 8.25 & 1.05 & 8.25 & 0.71 & 3.01 \\
\hline \multirow{2}{*}{$\begin{array}{l}\text { Employment status of } \\
\text { expert }\end{array}$} & No vs yes, fulltime & $-12.12^{* *}$ & 2.01 & $-9.02^{*}$ & 0.95 & -2.01 & 1.22 & $-5.09^{*}$ & 1.09 \\
\hline & Yes, parttime vs yes, fulltime & 2.52 & 9.36 & 1.04 & 8.25 & 1.05 & 8.25 & 0.71 & 3.01 \\
\hline \multirow[t]{3}{*}{ Formal OHSMS } & No vs yes & $-14.52^{* *}$ & 5.73 & $-12.73^{* *}$ & 2.81 & $-13.45^{* *}$ & 2.75 & $-3.15^{* *}$ & 3.25 \\
\hline & Previously vs yes & -0.83 & 5.01 & -0.88 & 3.24 & -3.15 & 9.75 & -2.42 & 8.53 \\
\hline & Implementing vs yes & -1.24 & 3.42 & -0.75 & 3.71 & -5.72 & 15.32 & -1.02 & 6.75 \\
\hline \multirow{2}{*}{$\begin{array}{l}\text { Senior manager } \\
\text { support of preven- } \\
\text { tive programs }\end{array}$} & No vs yes, appropriate & $-16.08^{* *}$ & 3.02 & $-12.45^{*}$ & 3.28 & $-10.25^{*}$ & 4.42 & $-4.71^{*}$ & 2.64 \\
\hline & $\begin{array}{l}\text { Yes, inappropriate vs yes, } \\
\text { appropriate }\end{array}$ & -2.01 & 5.75 & -4.54 & 9.42 & -0.85 & 3.45 & -2.65 & 8.73 \\
\hline
\end{tabular}

${ }^{*} p$-value $<0.05^{* *} p$-value $<0.01$.

with three uncertified companies. They found a significant difference in performance of risk assessment and corrective action according to OHSMS status. Whilst that study was undertaken before the COVID19 pandemic, we make the point that the risk of harm from the highly transmissible coronavirus had been widely and clearly announced. Organizations that manage their occupational risks using an OHSMS should be well placed to immediately prevent and mitigate the risks of COVID-19 as far as is reasonably practicable. Risk assessment is a systematic approach that uses available information to identify hazards and estimate risk associated with the hazards. This provides the requisite communication for transferring information about the condition of workplaces and affords consultation on best practice to manage the hazards using an appropriate indicator tool - such as the ILO PMAC [14].

Although risk assessment, management and communication in workplaces is essential for recognizing the threats and reducing the exposure to harm, other aspects of prevention and mitigation practice, including policy, planning and organizing, should not be disregarded. All four dimensions have a place in an effective OHSMS that is able to reduce workplace harm. Especially in unplanned situations such as the COVID-19 pandemic. Through sustained OHSMS, critical situations can be appropriated controlled. This involves creating, developing and maintaining policies that endorse an organization's commitment to health and safety, and formally express objectives such as the principles and structures to follow when there are uncertainties of health and safety at work [17]. In this study, policy, planning and organizing, was the weakest area of successful implementation with only one-third of organizations taking the required actions to prevent and mitigate COVID19. Misunderstanding of the need for training and developing workers competences, to promote ability, skills, and aptitudes in terms of risk prevention [17, 18] may be a part of this. In planning, employers must have both preventive planning and emergency planning. Preventive planning is the organized method of preparing policies and procedures designed to avoid accidents. The aim of emergency planning is to have the chance of reacting calmly in emergency situations 
to provide a quick and efficient response to any incident, and to reduce, as far as possible, its adverse effects $[16,19]$.

Many organizations did not have any arrangements for suspected and confirmed COVID-19 cases in place. This was the area with the largest issue of implementation of the PMAC. In the current situation of dealing with COVID-19 towards reducing the spread of the disease, ignorance by employers and top managers of appropriate actions to take in the context of suspected or confirmed COVID-19 cases at work can be threatening and dangerous for society. It is not just the ILO who have included this need for effective management of COVID-19 [11, 14], guidelines published by World Health Organization [12] also clearly emphasize the importance of making arrangements for suspected and confirmed COVID-19 cases at work. If the disease is to be contained, and society is to emerge from lockdown, then all workplaces must put measures in place to deal with suspected and confirmed cases of COVID-19 [20-22].

Our analyses of the relationship between organizational and managerial parameters of occupational safety and health and the four dimensions of the ILO PMAC found that these parameters were significantly related to PMAC scores, and hence effective COVID-19 actions. The construction sector, SMEs, and companies without any expertise in health and safety, companies that did not have a recognizable OHSMS and companies that did not have senior manager support were significant predictors of inadequate COVID-19 actions. The latter clearly illustrates the importance place of a proper OHSMS, and that a lack of support from a senior manager can be attributed to the absence of the necessary preventive measures for COVID-19, to mitigate for exposure to and spreading of this disease in the workplace. We can conjecture this has consequences in an increased prevalence of this disease in society.

\subsection{Limitations}

The most important limitations of this research are the cross-sectional methodology and the use of selfreport data. Nevertheless, the willingness of a broad range of organizations to report on their health and safety activity in relation to the pandemic, regardless of their situation allowed us to consider we had a representative sample. We are also aware that proper implementation of this tool depends on cooperation between employers, supervisors and workers, and future studies should also enquire on attitudes of all workers to partaking in suitable and sufficient prevention and mitigation of COVID-19 actions.

\section{Conclusion}

The ILO prevention and mitigation of COVID19 action at work checklist [14] provides a useful framework for assessing the sufficiency of the management of this disease in a workplace. Nevertheless, only half of our large study population were working within this validated framework and undertaking appropriate risk assessment for COVID-19 despite obviously being in the throes of a deadly pandemic. Clear recommendations, if not enforcement actions, are needed to promote formal OHSMS, and to gain senior manager support to ensure suitable risk assessments and prevention and mitigation actions. There is a particular requirement for clear messages to support PMAC activity across all industries in Iran, and especially in construction projects. There remains a need to understand the inaction of many organizations when the thousands of deaths in their own locality should provide a convincing rationale for taking steps to prevent and mitigate harm to their employees' health. We recommend that future research includes replication of this study, to examine the pervasiveness of inaction to mitigate workplace disease across the globe, and extension of its purpose, to understand how to make it easier for all to be protected from harm of COVID-19 in the workplace.

\section{Acknowledgments}

This study was supported by the Shiraz University of Medical Sciences.

\section{Conflict of interest}

None to report.

\section{Supplementary data}

The PMAC is available from https://dx.doi.org/ 10.3233/WOR-205303. 


\section{References}

[1] Béland L-P, Brodeur A, Wright T. The short-term economic consequences of Covid-19: exposure to disease, remote work and government response. IZA - Institute of Labor Economics. 2020.

[2] World Health Organization. Coronavirus disease (COVID19) Situation Report - 132. Available from https://reliefweb. int/sites/reliefweb.int/files/resources/20200531-covid-19sitrep-132.pdf

[3] Burdorf A, Porru F, Rugulies R. The COVID-19 (Coronavirus) pandemic: consequences for occupational health. Scandinavian Journal of Work, Environment \& Health. 2020(3):229-30.

[4] Atalan A. Is the lockdown important to prevent the COVID19 pandemic? Effects on psychology, environment and economy-perspective. Ann Med Surg. 2020;56:38-42.

[5] Sen B, Kar A. Economic impact of initial period of lockdown in Kolkata and suburbs. Stat J IAOS. 2021;37:47-55.

[6] Jena PK. Impact of Pandemic COVID-19 on education in India. Int J Current Res. 2020;12(7):12582-6.

[7] Zhang Y, Ma ZF. Impact of the COVID-19 Pandemic on mental health and quality of life among local residents in Liaoning Province, China: A cross-sectional study. Int $\mathbf{J}$ Environ Res Pub Health. 2020;17(7):2381.

[8] Gharibi V, Cousins R, Jahangiri M. Coronavirus-related opportunities for promoting occupational health and safety. Shiraz E-Med J. 2020;21(7):e104655.

[9] Gharibi V, Cousins R, Jahangiri M. Let's Get Back to Work: Preventive biological cycle management of the coronavirus in the workplace. WORK 2020;66:713-6.

[10] Huang A, Makridis C, Baker, M, Medeiros M, Guo Z. Understanding the impact of COVID-19 intervention policies on the hospitality labor market. Int J Hospitality Manag. 2020;91:102660.

[11] International Labor Organization. A safe and healthy return to work during the COVID-19 pandemic. Available at: https://www.ilo.org/wcmsp5/groups/public/—ed_protect/ —protrav/—safework/documents/briefingnote/wcms_7455 49.pdf. May 2020.

[12] World Health Organization. Critical preparedness, readiness and response actions for COVID-19: interim guidance, 22 March 2020. Available at: https://apps.who.int/iris/handle/ 10665/331511. Licence: CC BY-NC-SA 3.0 IGO
[13] International Labor Organization. Guidelines on occupational and health management systems, ILO-OSH 2001. Geneva. ISBN 92-2-111634-4

[14] International Labor Organization. Prevention and Mitigation of COVID-19 at Work Action Checklist. Available at: https://www.ilo.org/global/topics/safety-and-health-atwork/resources-library/publications/WCMS_741813/lang_ en/index.htm. 2020.

[15] Jahangiri M, Azmon H, Daneshvar A, Keshmiri F, Khaleghi $\mathrm{H}$, Besharati A, et al. Occupational health problems and safety conditions among small and medium-sized enterprises: A cross-sectional study in Shiraz, Iran. Ann Glob Health. 2019;85(1):51.

[16] Mohammadfam I, Kamalinia M, Momeni M, Golmohammadi R, Hamidi Y, Soltanian A. Evaluation of the quality of occupational health and safety management systems based on key performance indicators in certified organizations. Saf Health Work. 2017;8(2):156-61.

[17] Fernández-Muñiz B, Montes-Peón JM, Vázquez-Ordás CJ. Relation between occupational safety management and firm performance. Saf Sci. 2009;47(7):980-91.

[18] Daily E, Padjen P, Birnbaum M. A review of competencies developed for disaster healthcare providers: limitations of current processes and applicability. Prehospital Disaster Med. 2010;25(5):387-95.

[19] Choudhry RM, Fang D, Lingard H. Measuring safety climate of a construction company. J Construct Eng Manag. 2009;135(9):890-9.

[20] Belingheri M, Paladino ME, Riva MA. COVID-19: Health prevention and control in non-healthcare settings. Occup Med. 2020;70(2):82-3.

[21] Chughtai AA, Seale H, Islam MS, Owais M, Macintyre CR. Policies on the use of respiratory protection for hospital health workers to protect from coronavirus disease (COVID19). Int J Nurs Stud. 2020;105:103567.

[22] Rueda-Garrido JC, Vicente-Herrero M, del Campo M, Reinoso-Barbero L, de la Hoz RE, Delclos GL, et al. Return to work guidelines for the COVID-19 pandemic. Occup Med. 2020;70(5):300-305. 